\title{
Gonadotropins promote human ovarian cancer cell migration and invasion via a cyclooxygenase 2-dependent pathway
}

\author{
DINGQING FENG ${ }^{1}$, TINGTING ZHAO ${ }^{2}$, KEQIN YAN $^{1}$, HAIYAN LIANG $^{1}$, \\ JING LIANG $^{1}$, YING ZHOU ${ }^{3}$, WEIDONG ZHAO ${ }^{3,4}$ and BIN LING ${ }^{1}$ \\ ${ }^{1}$ Department of Obstetrics and Gynecology, China-Japan Friendship Hospital, Beijing 100029; \\ ${ }^{2}$ Department of Obstetrics, Wuxi Maternity and Child Health Hospital Affiliated to Nanjing Medical University, \\ Wuxi, Jiangsu 214002; ${ }^{3}$ Department of Obstetrics and Gynecology, Anhui Provincial Hospital Affiliated to \\ Anhui Medical University, Hefei, Anhui 230001; ${ }^{4}$ Department of Gynecology and Oncology, \\ Anhui Provincial Cancer Hospital, Hefei, Anhui 230009, P.R. China
}

Received January 20, 2017; Accepted June 22, 2017

DOI: $10.3892 /$ or.2017.5784

\begin{abstract}
It is generally accepted that ovarian cancer is associated with local elevation of gonadotropins (FSH and LH), with repeated ovulation and accompanying expression of inducible cyclooxygenase 2 (COX2). However, the roles of gonadotropins and the concomitant elevation of COX2 in the development of ovarian cancer have not been fully characterized. Herein, we report that excessive FSH/LH exposure did not induce proliferation in ovarian cancer cell lines but significantly promoted cell migration and invasion. Moreover, $\mathrm{FSH} / \mathrm{LH}$ treatment rapidly upregulated COX2 expression within $24 \mathrm{~h}$, whereas COX1 expression remained unchanged. Further results showed that enhancement of epithelial-mesenchymal transition (EMT) and upregulation of matrix metalloproteinase (MMP)2 and MMP9 contributed to the stimulatory effect of gonadotropins on cell migration and invasion; these effects were sufficiently blocked by a selective COX2 inhibitor. In conclusion, the present study suggests that gonadotropin-induced migration and invasion in ovarian cancer may be caused by EMT and MMP upregulation via a COX2-dependent pathway.
\end{abstract}

\section{Introduction}

Ovarian cancer is the leading cause of death among all gynecological malignancies. Despite advancements in the surgical and

Correspondence to: Dr Bin Ling, Department of Obstetrics and Gynecology, China-Japan Friendship Hospital, 2 Yinghua East Street, Beijing 100029, P.R. China

E-mail: lingbin.ling@gmail.com

Abbreviations: COXs, cyclooxygenases; PGs, prostaglandins; FSH, follicle stimulating hormone; LH, luteinizing hormone; FSHR, FSH receptor; LHR, LH receptor; OSE, ovarian surface epithelium; MMPs, matrix metalloproteinases; EMT, epithelial-mesenchymal transition

Key words: gonadotropins, COX2, migration and invasion, epithelial-mesenchymal transition, matrix metalloproteinases, ovarian cancer systemic treatment of ovarian cancer, the 5-year survival rate remains low (1). The etiology of ovarian cancer also remains largely unclear. Some evidence has indicated that endocrine factors may influence the tumorigenesis of ovarian cancer $(1,2)$. Ovarian cancer is more common in patients with elevation of the gonadotropins follicle stimulating hormone (FSH) and luteinizing hormone ( $\mathrm{LH})$, such as postmenopausal women or women who have received treatment for the induction of ovulation (3-5). Additionally, reduced risk for ovarian cancer is associated with multiple pregnancies, breastfeeding, and oral contraceptive use, which are all associated with lower levels of and reduced exposure to gonadotropins (1). Moreover, the concentrations of both FSH and LH in cysts and the tumor fluid of ovarian cancer are greater than in borderline tumors, benign tumors, and functional cysts of the ovary (6). The expression of FSH receptor (FSHR) and LH receptor (LHR) and the growthstimulating effect of their ligands in normal and neoplastic ovarian surface epithelium (OSE) and ovarian cancer cells have been demonstrated (2,4,7-9), although some reports are controversial $(10,11)$. Recently, some studies reported that treatment of ovarian cancer cells with gonadotropins in vitro enhances tumor angiogenesis and cell adhesion (2,12-14). Together, these observations suggest a crucial role for gonadotropins in the development and progression of ovarian cancer.

Cyclooxygenases (COXs) are a family of myeloperoxidases that catalyze the biosynthesis of prostaglandins (PGs) from arachidonic acid. COX1 is constitutively expressed in most tissues and plays a role in various physiological functions, whereas COX2 is transiently inducible by stimuli such as cytokines, growth factors, mitogens, tumor promoters and hormones and regulates inflammation, differentiation, mitogenesis, and angiogenesis (15-18). A number of studies have revealed that $\mathrm{COX} 2$ plays a critical role in the ovulatory process, whereas repeated ovulations were suggested to cause neoplastic transformation of the ovarian epithelium $(4,9,19,20)$. COX2 is rarely found in normal OSE but is present in premalignant ovarian inclusion cysts and is expressed in most ovarian cancer cells $(21,22)$. Additionally, to some extent, COX2 is an independent prognostic factor for overall survival in patients with ovarian cancer $(23,24)$. 
However, the roles of gonadotropins and of the concomitant elevation of COX2 in ovarian cancer development and progression have not been fully characterized. Therefore, we conducted the present study to examine the effect of gonadotropins on metastasis-related proteases and the invasiveness of ovarian cancer cells, thus to identify the key regulator of the gonadotropin pathway in ovarian cancer cells.

\section{Materials and methods}

Cell lines, drugs, inhibitors, and ovary tissues. The ovarian cancer cell lines SKOV3 and HO8910 were obtained from the American Type Culture Collection (ATCC, Manassas, VA, USA). The SKOV3 cell line was cultured in McCoy's 5A medium (Gibco, Grand Island, NY, USA) containing $10 \%$ fetal bovine serum (FBS, Gibco), $100 \mathrm{U} / \mathrm{ml}$ penicillin and $100 \mu \mathrm{g} / \mathrm{ml}$ streptomycin (Gibco) in a $5 \% \mathrm{CO}_{2}$ humidified atmosphere at $37^{\circ} \mathrm{C}$. The HO8910 cell line was cultured in RPMI-1640 (Gibco) under the above-mentioned culture conditions. Recombinant human FSH (75 IU) and LH (75 IU) were purchased from Merck Serono (Darmstadt, Germany). NS-398, a selective cyclooxygenase-2 (COX-2) inhibitor, was purchased from Beyotime (Shanghai, China). In this study, $10 \mu \mathrm{mol} / 1$ of NS-398 was used, which specifically inhibits COX2 enzyme activity but has no effect on COX1 activity (25).

The ovary tissues, used as positive controls for FSHR and LHR detection, were obtained from patients of ovarian cancer undergoing surgical excision. The investigation has been conducted in accordance with the ethical standards and according to the Declaration of Helsinki and has been approved by the ethics committee of the China-Japan Friendship Hospital. Written informed consent was obtained from each patient.

Immunocytochemical staining. SKOV3 and HO8910 cells were seeded on $18-\mathrm{mm}$ glass coverslips in a 6 -well culture plate and cultured for $48 \mathrm{~h}$. Coverslips were washed twice with PBS and fixed in ice-cold acetone for $5 \mathrm{~min}$. After the cells were washed twice with PBS, they were permeabilized with $0.1 \%$ Triton $\mathrm{X}-100$ in PBS for $5 \mathrm{~min}$ at room temperature. The coverslips were then washed with PBS and further incubated with normal goat serum (Boster, Wuhan, China) for $20 \mathrm{~min}$ at room temperature to block non-specific binding. The cells were then incubated with FSHR antibody (cat. PB1120; 1:200, Boster) or LHR antibody (cat. A01120; 1:500, Boster) at $4^{\circ} \mathrm{C}$ overnight. Rabbit IgG (cat. ab27478, Abcam, Cambridge, UK) was used as isotype control instead of primary antibody. The binding of the primary antibodies was visualized using a ChemMate Detection kit (cat. SV0002; Boster). The coverslips were lightly counterstained with Mayer's hematoxylin for $30 \mathrm{sec}$.

Cell viability assay. SKOV3 and HO8910 cells were seeded in 96-well plates at a density of 1000 cells/well and incubated for $24 \mathrm{~h}$. To examine the effect of FSH and LH on the viability of SKOV3 and HO8910 cells, the cells were treated with 100 and $500 \mathrm{mIU} / \mathrm{ml} \mathrm{FSH}$ and LH alone or in combination. The levels of gonadotropins were chosen because $100 \mathrm{mIU} / \mathrm{ml}$ are commonly achieved during ovarian hyperstimulation $(\mathrm{COH})$ and in 2-3 years after menopause $(10,26)$, while $500 \mathrm{mIU} / \mathrm{ml}$ is based on previous references $(11,27)$. Cell viability was measured
Table I. Specific primer sequences for RT-PCR and qRT-PCR.

\begin{tabular}{ll}
\hline Gene name & \multicolumn{1}{c}{ Primer sequences (5'-3') } \\
\hline FSHR $^{\text {a }}$ & F: TATGACTCAGGCTAGGGGTC \\
& R: ATAAGGAACCTGGGGACTGT \\
LHR $^{\text {a }}$ & F: CACCCCGATGTGCTCCTGAA \\
& R: TAGAGTGATGACGGTGAGGG \\
COX1 & F: CGCTCCAACCTTATCCCCAGTCCCC \\
& R: CTTTAGGCACAGAGGGCAGAATACG \\
COX2 & F: TCAAGTCCCTGAGCATCTACGGTT \\
& R: CTGTTGTGTTCCCGCAGCCAGATT \\
E-cadherin & F: ACAATGCCGCCATCGCTTAC \\
& R: AACTCTCTCGGTCCAGCCCA \\
Slug & F: GCCCCATTAGTGATGAAGAGGAAA \\
& R: AGCCCAGAAAAAGTTGAATAGGTC \\
Vimentin & F: AAGCAGGAGTCCACTGAGTA \\
& R: GCTTCAACGGCAAAGTTCTC \\
MMP2 & F: AACTACGATGATGACCGCAA \\
MMP9 & R: CTCCTGAATGCCCTTGATGT \\
& F: GTCTTCCAGTACCGAGAGAAAGCCT \\
& R: CAGGATGTCATAGGTCACGTAGCCC \\
& R: GATGTTCTGGAGAGCCCCG \\
&
\end{tabular}

aprimer sequences for RT-PCR. F, forward; R, reverse.

using an MTS cell proliferation kit (Promega, Madison, WI, USA) per the manufacturer's instructions. Assays were performed in triplicate and repeated three times.

Annexin V-FITC staining. Cell apoptosis was evaluated using an Annexin V-FITC apoptosis kit (eBioscience, San Diego, CA, USA) according to the manufacturer's instruction. In brief, SKOV3 and HO8910 cells were cultured in $10-\mathrm{cm}$ plates, and treated with $500 \mathrm{mIU} / \mathrm{ml} \mathrm{FSH}$ and LH for $24 \mathrm{~h}$. After that, cells were collected and washed with ice-cold PBS, and then resuspended in $100 \mu 1$ of binding buffer, containing $5 \mu \mathrm{l}$ of each Annexin V-FITC and propidium iodide (PI) solution. The samples were then examined using flow cytometer (FACSCalibur, BD Biosciences, Franklin Lakes, NJ, USA).

Cell migration and invasion assays. SKOV3 and HO8910 cells were grown in 6 -well plates at a density of $5 \times 10^{5}$ cells/well to nearly confluence and replaced the growth medium with serum-free medium for 5-h incubation to arrest cell growth. Then the cell monolayer was scraped with a pipette tip to generate scratch wounds. After the cells were washed three times to remove cell debris, they were cultured in serum-free medium containing $500 \mathrm{mIU} / \mathrm{ml} \mathrm{FSH} / \mathrm{LH}$ and $10 \mu \mathrm{mol} / \mathrm{l}$ NS-398 alone or in combination. Images were obtained, and the widths of the gaps were measured and analyzed at $24 \mathrm{~h}$. 
A

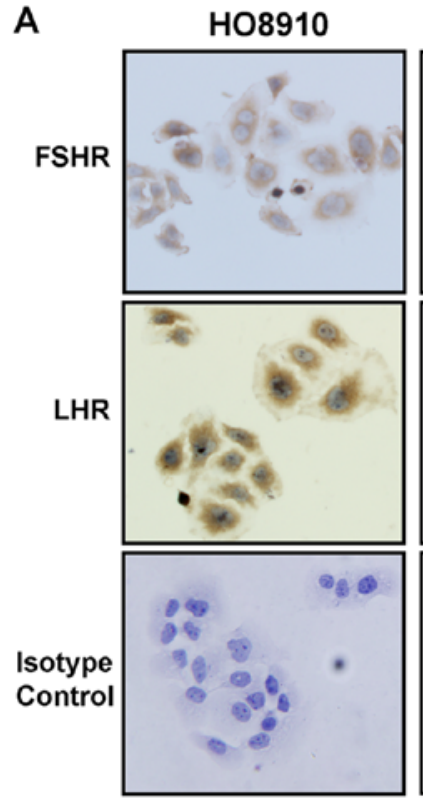

B

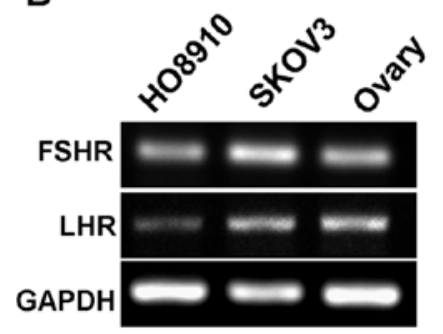

SKOV3

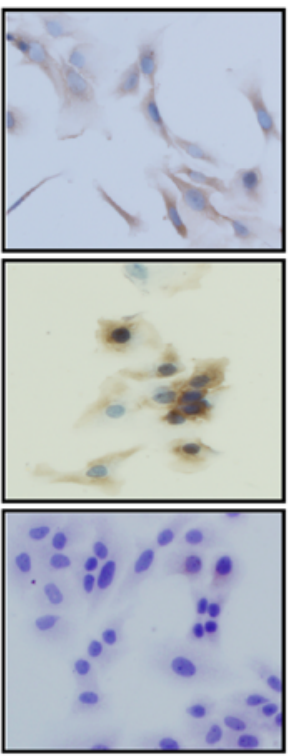

C

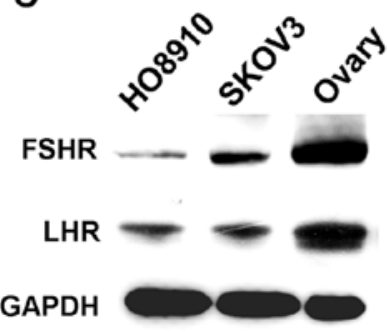

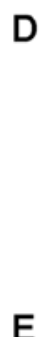

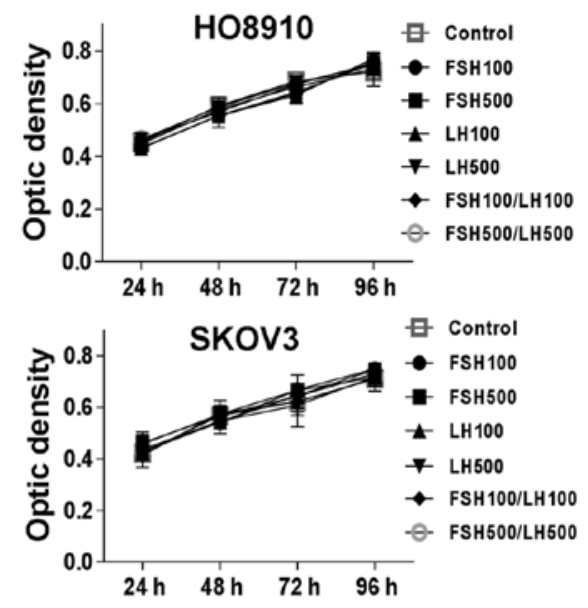

$\mathbf{F}$

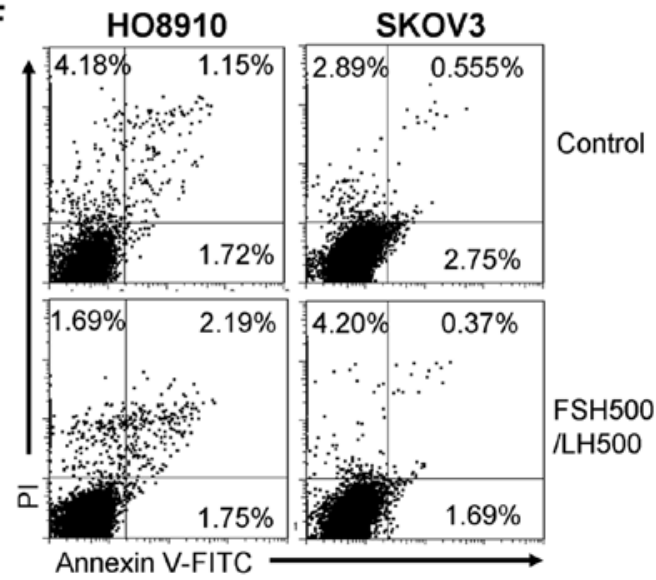

Figure 1. FSHR and LHR were expressed in SKOV3 and HO8910 cells but did not affect cell proliferation and apoptosis. Expression of FSHR and LHR was examined by immunocytochemical staining (A), RT-PCR (B), and western blotting (C). HO8910 and SKOV3 cells were treated with FSH and LH (0, 100, and $500 \mathrm{mIU} / \mathrm{ml}$ ) alone or in combination, but no changes in proliferation (D and E) and apoptosis (F) were observed.

Cell invasion was assessed using 24-well Transwell inserts (Corning Inc., Corning, NY, USA) with $8-\mu \mathrm{m}$ pores coated with $1 \mathrm{mg} / \mathrm{ml}$ Matrigel (BD Biosciences). Cells in the upper compartment of the chamber were suspended in culture medium with $1 \%$ FBS, and the lower chamber contained culture medium with $20 \%$ FBS. After cell adhesion, the medium in the upper chamber was replaced with fresh medium containing 1\% FBS, $500 \mathrm{mIU} / \mathrm{ml} \mathrm{FSH}$ and LH, FSH and LH in combination with $10 \mu \mathrm{mol} / \mathrm{l} \mathrm{NS}-398$, or NS-398 alone. After a 24-h incubation, the upper surface of the filter was erased carefully with a cotton swab, and then the cells that passed through the Matrigel matrix were fixed and stained with $0.05 \%$ crystal violet and counted in 5 random microscopic fields.

$R T-P C R$ and $q R T-P C R$. Total RNA was extracted using TRIzol (Invitrogen) and converted to cDNA using Superscript III reverse transcriptase (Takara, Shiga, Japan). The cDNA was amplified by PCR using Premix Ex Taq ${ }^{\mathrm{TM}}$ (Takara). Quantitative real-time PCR (qRT-PCR) was performed using an $\mathrm{iQ}^{\mathrm{TM}} \mathrm{SYBR}^{\circledR}$ Green Supermix kit (Bio-Rad Laboratories, Inc., Hercules, CA, USA) on a CFX96 Touch ${ }^{\mathrm{TM}}$ Real-time PCR instrument (Bio-Rad Laboratories, Inc.). The primer sets used in the RT-PCR and qRT-PCR are presented in Table I.

Antibodies and western blots. Antibodies specific to FSHR (cat.PB1120; 1:200) and LHR (cat. A01120; 1:200) were obtained from Boster. Antibodies specific to COX1 (cat. ab109025, 1:2000), COX2 (cat. ab52237, 1:1000), E-cadherin (cat. ab76055, 1:500), slug (cat. ab51772, 1:500), and vimentin (cat. ab133260, 1:500) were purchased from Abcam. Antibodies specific to MMP2 (cat. \#4022, 1:1000), MMP9 (cat. \#3852, 1:1000), and GAPDH (cat. \#2118, 1:2000) were obtained from Cell Signaling Technology (Beverly, MA, USA). Protein was prepared from the cells according to the kit manual (Thermo Fisher Scientific, Inc., Waltham, MA, USA). After electrophoresis, the proteins were transferred to polyvinylidene fluoride (PVDF, Merck Millipore, Darmstadt, Germany) membranes and probed with the indicated primary antibodies. Incubation with secondary antibodies of HRP-linked anti-rabbit IgG (cat. \#7074, Cell Signaling Technology) or HRP-linked antimouse IgG (cat. \#7076, Cell Signaling Technology) according to the species reactivity of primary antibodies was performed at room temperature for $1 \mathrm{~h}$. The blots were developed with chemiluminescent substrate (Thermo Fisher Scientific, Inc.), and autoradiography was performed with X-OMAT film (Kodak, Rochester, NY, USA).

Statistical analyses. The data are presented as the mean \pm SD. To assess the statistical significance of differences, an analysis of variance (ANOVA, SPSS software, version 13.0; SPSS Inc., USA) was performed. A P-value of $<0.05$ was considered to indicate a statistically significant difference. 

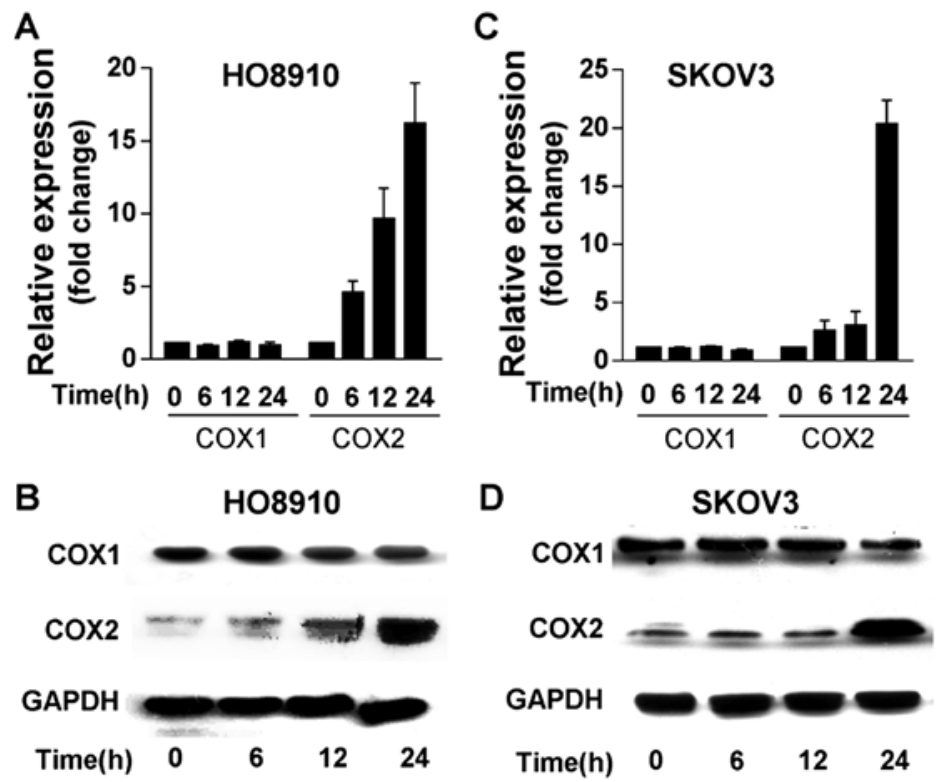

Figure 2. Effect of gonadotropins on COX1 and COX2 expression in ovarian cancer cells. HO8910 (A and B) and SKOV3 (C and D) cells were treated with $500 \mathrm{mIU} / \mathrm{ml} \mathrm{FSH} / \mathrm{LH}$ for 0 to $24 \mathrm{~h}$ as indicated. COX1 and COX2 expression was examined with qRT-PCR (A and C) and western blotting (B and D). COX2, but not COX1, was induced by FSH/LH in HO8910 and SKOV3 cells.

\section{Results}

Gonadotropins do not induce proliferation in ovarian cancer cells despite the expression of FSHR and LHR in these cells. Gonadotropins are considered to play a pivotal role in neoplastic conversion and growth potential via their receptors FSHR and LHR during the tumorigenesis of ovarian cancers (9). In this study, we first showed the expression of FSHR and LHR in SKOV3 and HO8910 cells with immunocytochemical staining, RT-PCR, and western blotting (Fig. 1A-C). Then, we determined the effect of gonadotropins on the growth of SKOV3 and HO8910 cells. To our surprise, neither FSH nor LH stimulated the growth of ovarian cancer cells at either tested concentration $(100$ and $500 \mathrm{mIU} / \mathrm{ml})$. Furthermore, the combination of FSH and LH also failed to increase the viable cell numbers as compared to prior treatment (Fig. 1D and E). In addition, no significant variations in the ratio of cell apoptosis were observed in either cell line after treatment with $500 \mathrm{mIU} / \mathrm{ml} \mathrm{FSH}$ and $\mathrm{LH}$ for $24 \mathrm{~h}$ (Fig. 1F).

Gonadotropins induce COX2 upregulation in ovarian cancer cells. It is well documented that COX2 is an inducible, immediate early gene that, in addition to inflammatory stimuli, participates in the process of malignant cell transformation, while COX1 is constitutively expressed in most tissues (15). In our study, COX2 was rapidly induced after treatment with $500 \mathrm{mIU} / \mathrm{ml} \mathrm{FSH}$ combined with $500 \mathrm{mIU} / \mathrm{ml} \mathrm{LH}$ for $6 \mathrm{~h}$ and was steadily upregulated up to $24 \mathrm{~h}$ after continued treatment in HO8910 cells (Fig. 2A and B). In SKOV3 cells treated with FSH and LH, the expression of COX2 in SKOV3 cells increased slowly and then elevated sharply at $24 \mathrm{~h}$ (Fig. 2C and D). In both cell lines, COX1 maintained stable expression levels with or without FSH and LH treatment (Fig. 2). These results demonstrate that $\mathrm{COX} 2$ is selectively upregulated by FSH and LH in SKOV3 and HO8910 cells.
Gonadotropins promote ovarian cancer cell migration and invasion. To further investigate the role of excessive exposure to gonadotropins in the development and progression of ovarian cancer, the migration and invasion activities of SKOV3 and HO8910 cells with or without gonadotropin treatment was analyzed using wound-healing and Transwell assays, respectively. At $24 \mathrm{~h}$ after the scratch injury, the SKOV3 cells treated with $500 \mathrm{mIU} / \mathrm{ml} \mathrm{FSH}$ and LH were able to cover $95.3 \%$ of the scratch, whereas the control cells only covered 54\%. Importantly, NS-398, a specific COX2 inhibitor, blocked SKOV3 cell migration even in the presence of FSH and LH, which resulted in only $29 \%$ coverage of the scratch (Fig. 3). Similarly, in HO8910 cells, $500 \mathrm{mIU} / \mathrm{ml} \mathrm{FSH} \mathrm{and} \mathrm{LH}$ significantly promoted cell migration compared to the control (73.3\% compared with 38\%), while NS-398 attenuated the effect of gonadotropins (18.3\%) (Fig. 3). The invasion assays also showed that treatment with $500 \mathrm{mIU} / \mathrm{ml} \mathrm{FSH}$ and $\mathrm{LH}$ significantly promoted ovarian cancer cell invasion, whereas cell invasion was effectively blocked by NS-398 (Fig. 4). As low level of COX2 expressed in ovarian cancer cells without FSH/LH stimulation, NS-398 treatment alone also, to some extent, showed inhibition effects in both cell migration and invasion. Collectively, these results demonstrated that the combination of FSH and LH notably enhanced ovarian cancer cell migration and invasion in vitro, but these effects were markedly inhibited by NS-398.

Gonadotropin-induced cell migration and invasion occur due to COX2-dependent enhancement of epithelial-mesenchymal transition (EMT) and upregulation of MMP2 and MMP9. EMT enables polarized epithelial cells to lose adherence, thus enhancing the migratory capacity and acquirement of invasive properties in these cells. In our study, the results showed that treatment with FSH and LH led to ongoing downregulation of E-cadherin and simultaneous upregulation of slug and vimentin in SKOV3 cells (Fig. 5). Furthermore, FSH and LH 
A

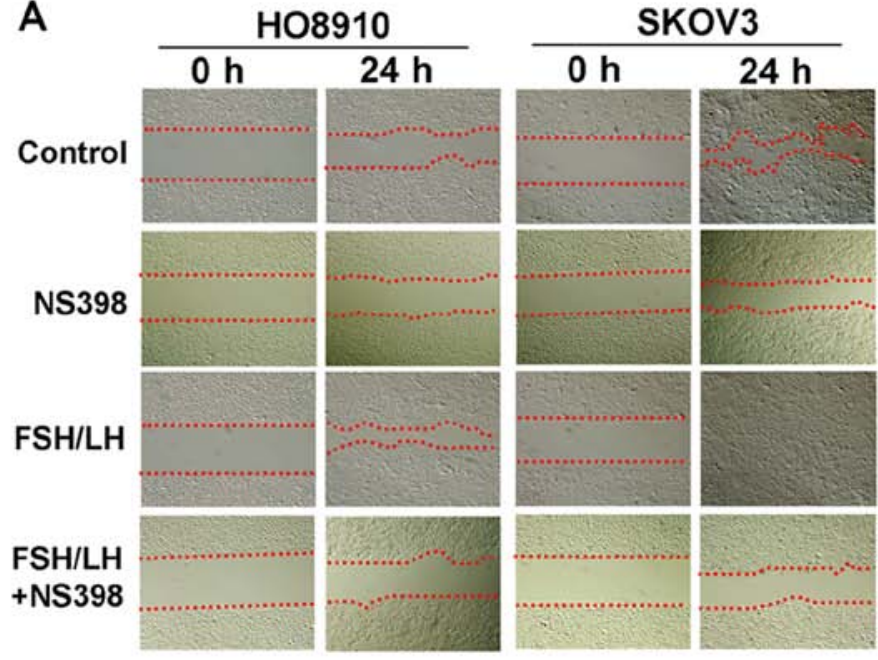

B

H08910

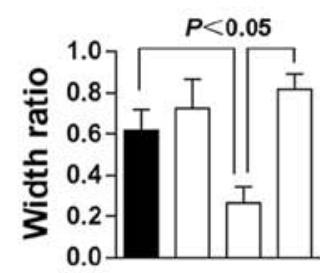

$\mathrm{FSH} / \mathrm{LH}-+++$

NS398 - + +
SKOV3

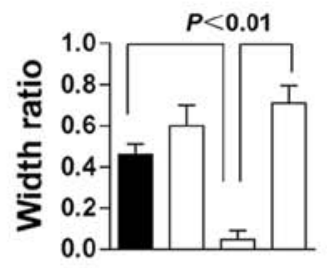

$\mathrm{FSH} / \mathrm{LH}-+++$

NS398 - + - +

Figure 3. Gonadotropins promote ovarian cancer cell migration, whereas this effect was specifically suppressed by a selective COX2 inhibitor. (A) After scratch injury, HO8910 and SKOV3 cells were treated with $500 \mathrm{mIU} / \mathrm{ml} \mathrm{FSH} / \mathrm{LH}$ for $24 \mathrm{~h}$ in the presence or absence of $10 \mu \mathrm{mol} / 1 \mathrm{NS}-398$, or NS-398 alone. (B) The wound distances were measured, and cell migration was expressed as the average percentage of wound closure compared with time zero.

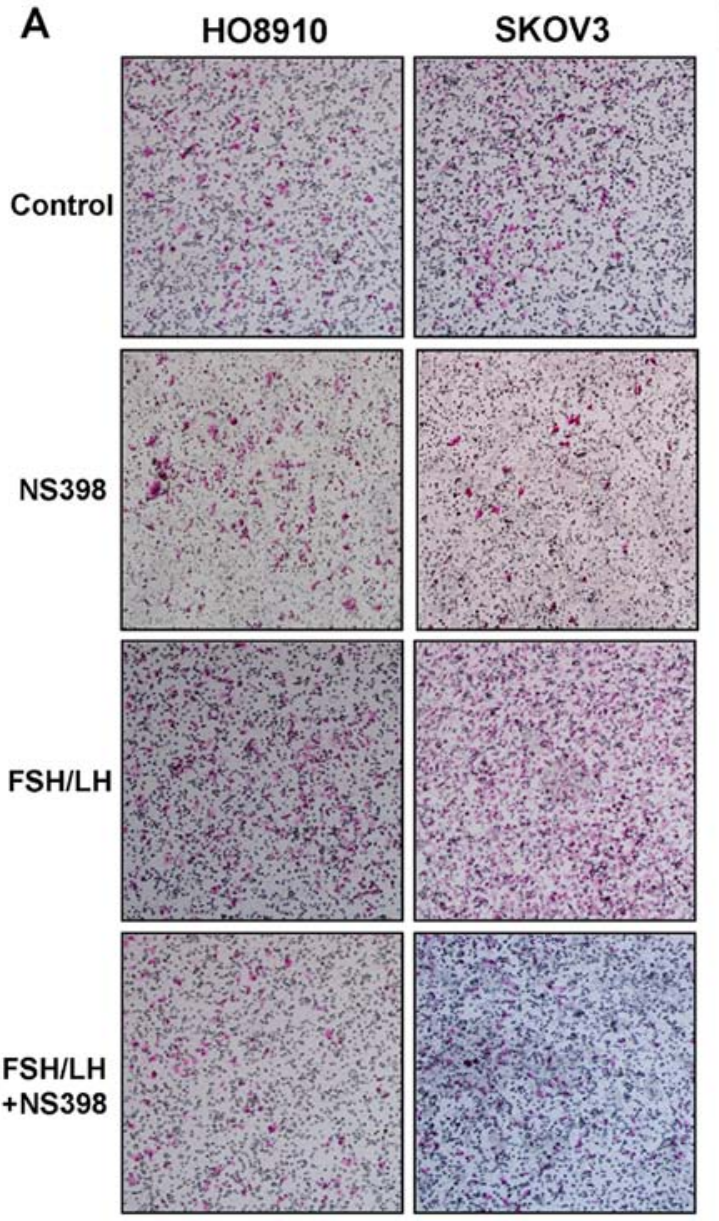

B
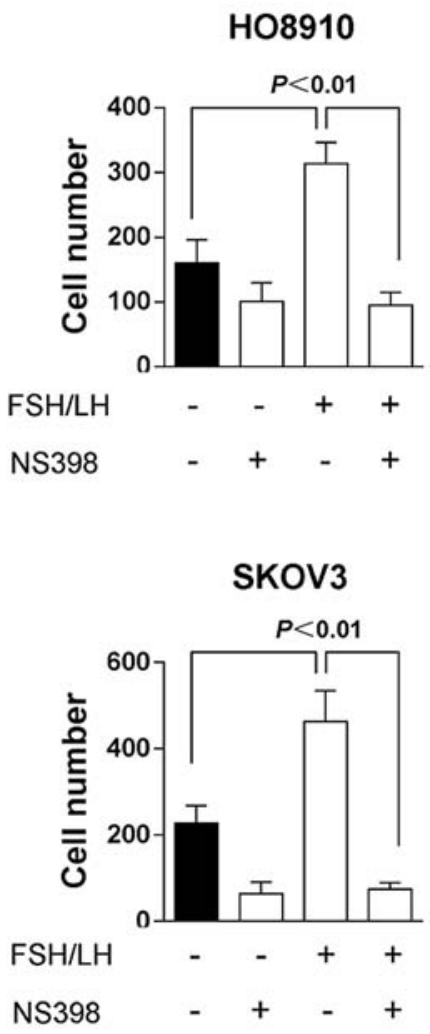

Figure 4. A selective COX2 inhibitor suppresses gonadotropin-induced cell invasion in ovarian cancer cells. (A) HO8910 and SKOV3 cells were treated with $500 \mathrm{mIU} / \mathrm{ml} \mathrm{FSH} / \mathrm{LH}$ for $24 \mathrm{~h}$ in the presence or absence of $10 \mu \mathrm{mol} / 1 \mathrm{NS}-398$, or NS-398 alone. Cells that passed through the Matrigel-precoated filters were stained with $0.05 \%$ crystal violet. (B) Cell invasion was quantified by determining the average number of cells per microscopic field.

stimulated increased expression of MMP2 and MMP9, which indicates that proteolysis, to some extent, plays a role in cell invasion induced by gonadotropins (Fig. 5). Notably, the effects of EMT and MMP expression induced by gonadotropins were specifically blocked by NS-398. However, neither mRNA nor protein of COX2 expression was inhibited obviously by NS-398 (Fig. 5), which indicated that NS-398 just inhibited the enzyme activity but not the expression of COX2. In addition, 
A
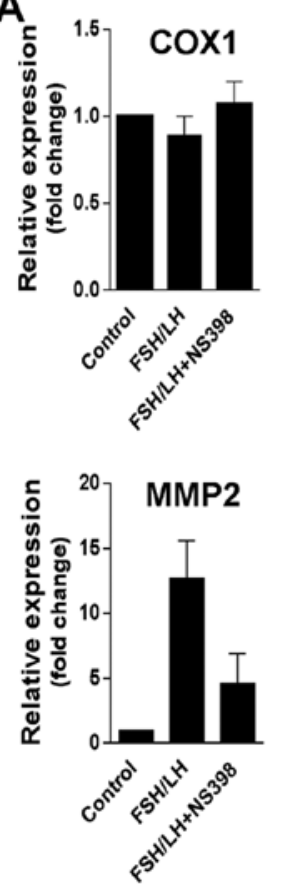
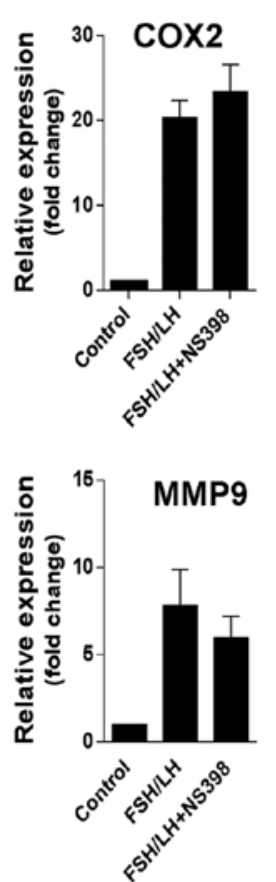
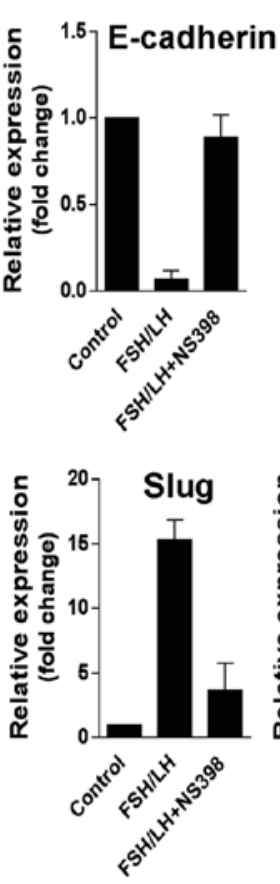

B

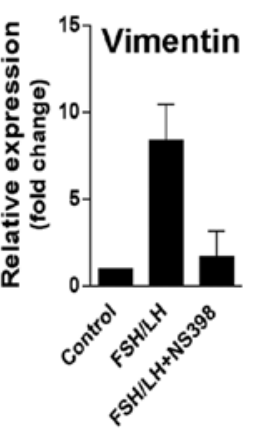

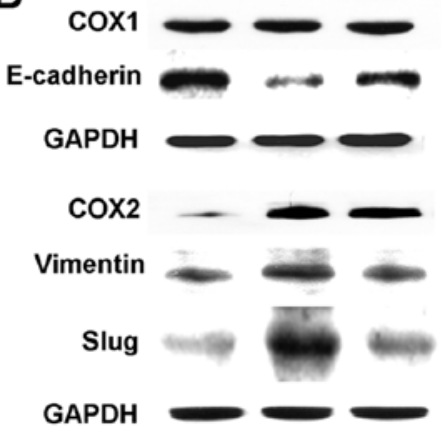

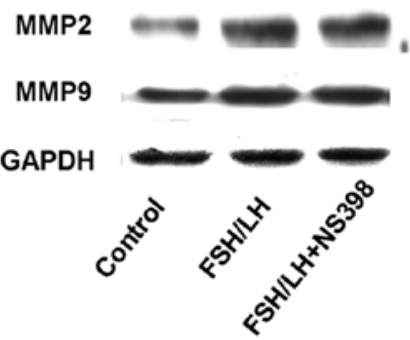

Figure 5. Gonadotropins enhanced EMT and MMP upregulation via a COX2-dependent pathway. SKOV3 cells were treated with 500 mIU/ml FSH/LH for $24 \mathrm{~h}$ in the presence or absence of $10 \mu \mathrm{mol} / 1 \mathrm{NS}-398$. The expression of COX1, COX2, E-cadherin, slug, vimentin, MMP2, and MMP9 was measured by qRT-PCR (A) and western blotting (B).

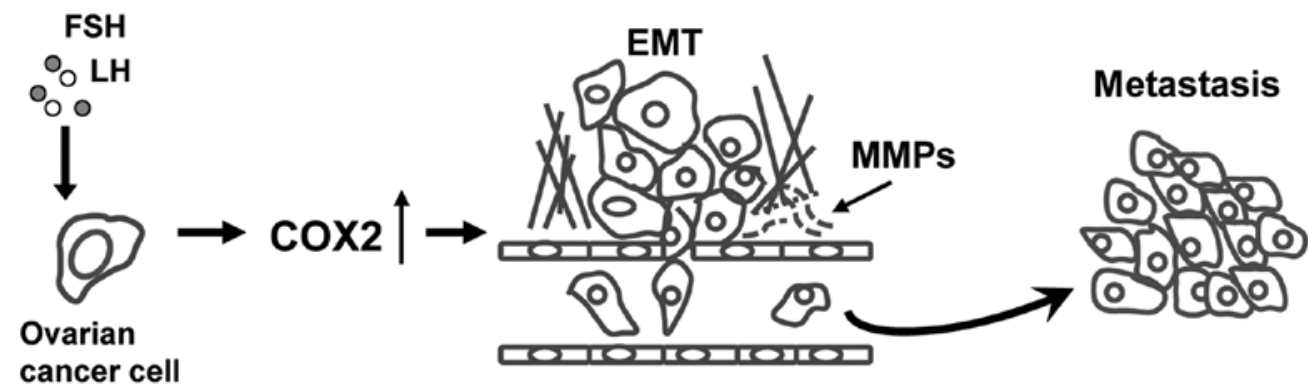

Figure 6. A model of how gonadotropins promote cell migration and invasion via a COX2-dependent pathway in ovarian cancer.

the same changes were observed in HO8910 cells (data not shown). Taken together, the promotion of cell migration and invasion by gonadotropins in ovarian cancer is mostly dependent on the activation of COX2 pathway (Fig. 6).

\section{Discussion}

High levels of gonadotropins during ovulation, loss of gonadal negative feedback during menopause, and premature ovarian failure are all thought to be critical risk factors for ovarian cancer (1-3). FSH and LH levels in the cyst fluid from ovarian malignant tumors are significantly higher than those from benign tumors $(6,28)$. Furthermore, gonadotropins not only induce both ovarian cancer cell proliferation and migration but also stimulate normal OSE proliferation $(4,9)$. In this study, our data showed that the combination of $500 \mathrm{mIU} / \mathrm{ml} \mathrm{FSH}$ and LH significantly promotes ovarian cancer cell migration and invasion within $24 \mathrm{~h}$ compared to cells not exposed to gonadotropins. However, we did not observe proliferation in ovarian cancer cells treated with 100 and $500 \mathrm{mIU} / \mathrm{ml} \mathrm{FSH}$ and LH alone or in combination. As previous studies have shown, the association of gonadotropins with the proliferation of OSE and ovarian cancer cells is inconsistent and has been shown to be stimulatory, irrelevant, or even inhibitory $(2,11,13)$. Variations in the concentration of gonadotropin and density of cultured cells and gonadotropin receptors may, to some extent, contribute to these discrepancies.

To date, there is increasing evidence that the expression of COX2 is upregulated in a variety of human cancers, such as colorectal, skin, liver, breast, and lung cancers (29-33). Elevated COX2 expression also has been detected in malignant ovarian tumors, and high levels of COX2 expression are correlated with poor prognosis and decreased overall survival in human ovarian cancer $(9,23)$. Our results showed that excessive exposure to gonadotropins induced significant upregulation of COX2 expression in SKOV3 and HO8910 cells, whereas COX1 expression was unchanged. Moreover, treatment with gonadotropins noticeably promoted cell migration and invasion in 
SKOV3 and HO8910 cells, but these effects can be sufficiently blocked by NS-398. Therefore, these data indicate that COX2 plays an essential role in gonadotropin-induced cell migration and invasion.

With further exploration of the mechanisms underlying the above mentioned effects, we demonstrated that treatment with FSH and LH enhanced the expression of MMPs and epithelialmesenchymal transition in both SKOV3 and HO8910 cells. MMPs are a family of highly homologous, protein-degrading, zinc-dependent enzyme endopeptidases; among the MMPs, MMP2 and MMP9 are notably correlated with tumor invasion and metastasis (34). EMT, a key event in the promotion of neoplastic progression and the development of metastasis, is characterized by multiple molecular changes, including downregulation of E-cadherin, upregulation of its transcriptional repressors snail and slug, and augmentation of the expression of vimentin, fibronectin, and collagen (35). In our study, inhibition of COX2 by NS-398 restored E-cadherin expression and repressed slug, vimentin, MMP2 and MMP9 expression, which significantly blocked cell migration and invasion induced by gonadotropins. Experimental studies have also shown that COX2 inhibitors block tumor growth and enhance anticancer activity when combined with chemotherapeutic drugs, mainly through antiangiogenic and proapoptotic effects $(36,37)$. Recently, Majumder and his colleagues reported that COX2 upregulation or overexpression in human breast cancer cells induced breast cancer stem cells via EP4/PI3K/AKT/NOTCH/WNT pathway and promoted tumor growth and metastasis in immunodeficient mice, which can be reliably blocked by COX2 inhibitor or EP4 antagonist (38). These data further suggest that COX2 can serve as not only a predictor of disease outcome but also a target for the treatment of ovarian cancers.

In summary, the current study, to a certain extent, demonstrates that gonadotropins promote cell migration and invasion via induction of COX2 expression in ovarian cancer cells, whereas specific inhibitors of COX2 significantly prevent these effects. However, some limitations of this study must be highlighted, such as incomplete elimination of endogenous COX2, an inappropriate method for detection of cell proliferation, lack of enough evidence from other ovarian cancer cell lines and primary cells to further support the work. Thus, to get a more reliable conclusion, further well-designed investigations are needed.

\section{Acknowledgements}

We would like to thank Dr Zhongjun Dong (School of Medicine, Tsinghua University) for the helpful comments and for critically reading of the manuscript. This work was supported by the National Natural Science Foundation of China (81372779 and 81372777) and the Anhui Provincial Natural Science Foundation (110406 M176).

\section{References}

1. Gharwan H, Bunch KP and Annunziata CM: The role of reproductive hormones in epithelial ovarian carcinogenesis. Endocr Relat Cancer 22: R339-R363, 2015.

2. Mertens-Walker I, Baxter RC and Marsh DJ: Gonadotropin signalling in epithelial ovarian cancer. Cancer Lett 324: 152-159, 2012.
3. Paulson RJ: Treatment of infertility and the risk of ovarian cancer: Are the data reassuring? Fertil Steril 105: 605-606, 2016.

4. Burdette JE, Kurley SJ, Kilen SM, Mayo KE and Woodruff TK: Gonadotropin-induced superovulation drives ovarian surface epithelia proliferation in CD1 mice. Endocrinology 147: 2338-2345, 2006.

5. Rodgers LH, Oh E, Young AN and Burdette JE: Loss of PAX8 in high-grade serous ovarian cancer reduces cell survival despite unique modes of action in the fallopian tube and ovarian surface epithelium. Oncotarget 7: 32785-32795, 2016.

6. Rzepka-Górska I, Chudecka-Głaz A and Kosmowska B: FSH and $\mathrm{LH}$ serum/tumor fluid ratios and malignant tumors of the ovary. Endocr Relat Cancer 11: 315-321, 2004.

7. Saddick SY: In vitro regulation of sheep ovarian surface epithelium (OSE) proliferation by local ovarian factors. Saudi J Biol Sci 19: 285-290, 2012.

8. Mertens-Walker I, Bolitho C, Baxter RC and Marsh DJ: Gonadotropin-induced ovarian cancer cell migration and proliferation require extracellular signal-regulated kinase 1/2 activation regulated by calcium and protein kinase $\mathrm{C}\{$ delta\}. Endocr Relat Cancer 17: 335-349, 2010.

9. Hilliard TS, Modi DA and Burdette JE: Gonadotropins activate oncogenic pathways to enhance proliferation in normal mouse ovarian surface epithelium. Int J Mol Sci 14: 4762-4782, 2013.

10. Tourgeman DE, Lu JJ, Boostanfar R, Amezcua C, Felix JC and Paulson RJ: Human chorionic gonadotropin suppresses ovarian epithelial neoplastic cell proliferation in vitro. Fertil Steril 78: 1096-1099, 2002.

11. Ivarsson K, Sundfeldt K, Brännström M, Hellberg P and Janson PO: Diverse effects of FSH and LH on proliferation of human ovarian surface epithelial cells. Hum Reprod 16: 18-23, 2001.

12. Kim D, Lee J and Johnson AL: Vascular endothelial growth factor and angiopoietins during hen ovarian follicle development. Gen Comp Endocrinol 232: 25-31, 2016.

13. Tzuman YC, Sapoznik S, Granot D, Nevo N and Neeman M: Peritoneal adhesion and angiogenesis in ovarian carcinoma are inversely regulated by hyaluronan: The role of gonadotropins. Neoplasia 12: 51-60, 2010.

14. Lau M-T, Wong AST and Leung PCK: Gonadotropins induce tumor cell migration and invasion by increasing cyclooxygenases expression and prostaglandin $\mathrm{E}(2)$ production in human ovarian cancer cells. Endocrinology 151: 2985-2993, 2010.

15. Harris RE: Cyclooxygenase-2 (cox-2) and the inflammogenesis of cancer. Subcell Biochem 42: 93-126, 2007.

16. Moran EM: Epidemiological and clinical aspects of nonsteroidal anti-inflammatory drugs and cancer risks. J Environ Pathol Toxicol Oncol 21: 193-201, 2002.

17. Pang LY, Hurst EA and Argyle DJ: Cyclooxygenase-2: A role in cancer stem cell survival and repopulation of cancer cells during Therapy. Stem Cells Int 2016: 2048731, 2016.

18. Wang X, Baek SJ and Eling T: COX inhibitors directly alter gene expression: Role in cancer prevention? Cancer Metastasis Rev 30: 641-657, 2011.

19. Duffy DM: Novel contraceptive targets to inhibit ovulation: The prostaglandin E2 pathway. Hum Reprod Update 21: 652-670, 2015.

20. Rask K, Zhu Y, Wang W, Hedin L and Sundfeldt K: Ovarian epithelial cancer: A role for PGE2-synthesis and signalling in malignant transformation and progression. Mol Cancer 5: 62, 2006.

21. Li S, Miner K, Fannin R, Carl Barrett J and Davis BJ: Cyclooxygenase-1 and 2 in normal and malignant human ovarian epithelium. Gynecol Oncol 92: 622-627, 2004.

22. Menczer J: Cox-2 expression in ovarian malignancies: A review of the clinical aspects. Eur J Obstet Gynecol Reprod Biol 146: 129-132, 2009.

23. Lee JY, Myung SK and Song YS: Prognostic role of cyclooxygenase-2 in epithelial ovarian cancer: A meta-analysis of observational studies. Gynecol Oncol 129: 613-619, 2013.

24. Whynott RM, Manahan P and Geisler JP: Vascular endothelial growth factor (VEGF) and cyclooxygenase 2 (COX 2) immunostaining in ovarian cancer. Eur J Gynaecol Oncol 37: 164-166, 2016.

25. Futaki N, Takahashi S, Yokoyama M, Arai I, Higuchi S and Otomo S: NS-398, a new anti-inflammatory agent, selectively inhibits prostaglandin $\mathrm{G} / \mathrm{H}$ synthase/cyclooxygenase (COX-2) activity in vitro. Prostaglandins 47: 55-59, 1994. 
26. Choi JH, Wong AS, Huang HF and Leung PC: Gonadotropins and ovarian cancer. Endocr Rev 28: 440-461, 2007.

27. Wright JW, Toth-Fejel S, Stouffer RL and Rodland KD: Proliferation of rhesus ovarian surface epithelial cells in culture: lack of mitogenic response to steroid or gonadotropic hormones. Endocrinology 143: 2198-2207, 2002.

28. Barczyński B, Rogala E, Nowicka A, Nurzyńska-Flak J and Kotarski J: Pelvic pain, free fluid in pelvis, and human chorionic gonadotropin serum elevation: Recurrence of malignant ovarian germ-cell tumor or early pregnancy? Eur J Gynaecol Oncol 34: 489-492, 2013

29. Guo Z, Jiang J-H, Zhang J, Yang HJ, Yang FQ, Qi YP, Zhong YP Su J, Yang RR, Li LQ, et al: COX-2 promotes migration and invasion by the side population of cancer stem cell-like hepatocellular carcinoma cells. Medicine (Baltimore) 94: e1806, 2015.

30. Majumder M, Landman E, Liu L, Hess D and Lala PK: COX-2 elevates oncogenic miR-526b in breast cancer by EP4 activation. Mol Cancer Res 13: 1022-1033, 2015.

31. Liu Y, Sun H, Hu M, Zhang Y, Chen S, Tighe S and Zhu Y: The Role of cyclooxygenase- 2 in colorectal carcinogenesis. Clin Colorectal Cancer: Oct 6, 2016 (Epub ahead of print).

32. Hua H-K, Jin C, Yang L-J, Tao S-Q and Zhu X-H: Expression of cyclooxygenase- 2 in squamous cell carcinoma and keratoacanthoma and its clinical significance. Cell Biochem Biophys 72: $475-480,2015$
33. Maeng H-J, Lee W-J, Jin Q-R, Chang J-E and Shim W-S: Upregulation of COX-2 in the lung cancer promotes overexpression of multidrug resistance protein 4 (MRP4) via PGE2-dependent pathway. Eur J Pharm Sci 62: 189-196, 2014.

34. Tang Y, Lv P, Sun Z, Han L, Zhou W and Zhou W: 14-3-3ק Promotes migration and invasion of human hepatocellular carcinoma cells by modulating expression of MMP2 and MMP9 through PI3K/Akt/NF- $\kappa$ B pathway. PLoS One 11: e0146070, 2016.

35. Bottoni P, Isgrò MA and Scatena R: The epithelial-mesenchymal transition in cancer: A potential critical topic for translational proteomic research. Expert Rev Proteomics 13: 115-133, 2016.

36. Kurtova AV, Xiao J, Mo Q, Pazhanisamy S, Krasnow R, Lerner SP, Chen F, Roh TT, Lay E, Ho PL, et al: Blocking PGE2-induced tumour repopulation abrogates bladder cancer chemoresistance. Nature 517: 209-213, 2015.

37. Zhang G, Panigrahy D, Hwang SH, Yang J, Mahakian LM, Wettersten HI, Liu JY, Wang Y, Ingham ES, Tam S, et al: Dual inhibition of cyclooxygenase-2 and soluble epoxide hydrolase synergistically suppresses primary tumor growth and metastasis. Proc Natl Acad Sci USA 111: 11127-11132, 2014.

38. Majumder M, Xin X, Liu L, Tutunea-Fatan E, RodriguezTorres M, Vincent K, Postovit LM, Hess D and Lala PK: COX-2 induces breast cancer stem cells via EP4/PI3K/AKT/NOTCH/ WNT axis. Stem Cells 34: 2290-2305, 2016. 